\title{
EMBRYONIC DEVELOPMENT OF THE LEECH NERVOUS SYSTEM: PRIMARY AXON OUTGROWTH OF IDENTIFIED NEURONS ${ }^{1}$
}

\author{
JOHN Y. KUWADA*,2 AND ANDREW P. KRAMER \\ * Department of Biology, University of California, San Diego, La Jolla, California 92093 and $\ddagger$ Department of Molecular Biology, \\ University of California, Berkeley, California 94720
}

Received January 21, 1983; Revised May 2, 1983; Accepted May 5, 1983

\begin{abstract}
This paper describes the embryonic development of the leech nervous system and focuses on the differentiation of two identified pressure sensory $(P)$ neurons, the $P_{\mathrm{D}}$ and $\mathrm{P}_{\mathrm{V}}$ neurons. In the adult leech the $\mathrm{P}$ neurons have distinctive cell body locations in the central nervous system (CNS), different peripheral axon branching patterns, and different receptive field territories in the skin. The embryonic $\mathrm{P}$ neurons also have distinct and reproducible locations in the CNS and have been studied with recording and dye-filled microelectrodes from the time the first growth cones are projected from their somata.

The peripheral axons of the $\mathbf{P}$ neurons are among the earliest peripheral axons to develop and may play an important role in the formation of peripheral nerves. The first or primary peripheral axons of the $\mathrm{P}$ neurons grow directly to their separate target territories. The specificity of the $\mathrm{P}$ neurons for their targets is probably not due to temporal differences in the outgrowth of their primary axons. Instead, the $P_{D}$ neuron seems to exhibit a preference early in embryogenesis for the target of its primary axon despite an apparent opportunity to occupy the target of the $\mathrm{P}_{\mathrm{V}}$ primary axon. It is hypothesized that the primary peripheral axons of the $\mathrm{P}$ neurons are among the first axons projected from the CNS and follow environmental cues to reach and innervate their target territories.
\end{abstract}

Some longstanding issues concerning how neurons form specific connections during development have been clarified recently by following the growth of identified neurons or identified groups of neurons. Landmesser and colleagues (I andmesser and Morris, 1975; I andmesser, 1978a, b; Lance-Jones and Landmesser, 1980a, b) have demonstrated that the outgrowth of axons from identified chick motoneuron pools were from the beginning highly selective. Furthermore, experiments in which the embryonic spinal cord was partially deleted (Lance-Jones and Landmesser, 1980a) or reversed (Lance-Jones and Landmesser, 1980b) or the limb rotated about the dorsoventral axis (Ferguson, 1981) indicated that each motoneuron has an identity prior to muscle innervation and

\footnotetext{
1 This research was supported by a National Science Foundation postdoctoral fellowship to J. Y. K., National Institutes of Health postdoctoral fellowships to J. Y. K. and A. P. K., and research grants from the National Science Foundation (Grants BNS 79-23459 and BNS 79-12400) and the National Institutes of Health (Grant NS 12818). We thank W. B. Kristan for many useful discussions and C. S. Goodman, W. A. Harris, W. B. Kristan, and G. S. Stent for helpful comments on the manuscript.

${ }^{2}$ To whom correspondence should be addressed, at Department of Biological Sciences, Stanford University, Stanford, CA 94305.
}

that it recognizes and chooses specific pathways to find its target muscle. Similar proposals have been made concerning the formation of peripheral and central nervous system pathways by identified neurons in the embryonic grasshopper (Bate, 1976; Keshishian, 1980; Bate and Grunewald, 1981; Ho and Goodman, 1982; Goodman et al., 1982; Raper et al., 1983a, b).

The leech nervous system, which contains a relatively small number of neurons, many of which are identified as individuals and as members of neural circuits (Muller et al., 1981), is also an attractive preparation for investigating developmental issues. The leech has already proven useful in studies of cell lineage (Whitman, 1878, 1887; Weisblat et al., 1978, 1980a, b). Furthermore, the glossiphoniid leech Haementaria ghilianii (Sawyer et al., 1981) has large eggs which develop into embryos with nervous systems amenable to intracellular physiological and morphological analysis. This paper addresses the issue of neuronal specificity by describing the development of the well characterized leech mechanosensory neurons (Nicholls and Baylor, 1968; Muller and McMahan, 1976; Kramer and Goldman, 1981) as well as characterizing the embryonic development of the $H$. ghilianii nervous system. Some of these results have been 
reported previously in abstract form (Kuwada and Kris$\tan , 1981)$.

\section{Materials and Methods}

Leech embryos. Embryos of the leech Haementaria ghilianii were supplied by a laboratory breeding colony. Leeches were kept in 5-gallon aquaria filled with deionized water to which was added $0.63 \mathrm{mM} \mathrm{NaCl}, 0.07 \mathrm{mM}$ $\mathrm{CaCl}_{2}, 0.07 \mathrm{mM} \mathrm{MgCl}_{2}$, and $0.005 \mathrm{mM} \mathrm{K}_{2} \mathrm{SO}_{4}$ to approximate the cation concentrations of their natural habitat, marsh water, and $1 \mathrm{mM} 2-(N$-morpholino)ethane sulfonate for buffering at $\mathrm{pH}$ 5.9. The water was changed daily. The leech colony was housed in a room maintained at $27^{\circ} \mathrm{C}$ with the light/dark cycle controlled to expose the leeches to $14 \mathrm{hr}$ of continuous light daily. Details of the care, growth, and reproduction of $H$. ghilianii can be found in Sawyer et al. (1981).

Embryos were allowed to develop in their cocoons on the mother leech for 10 to 11 days before removal with forceps and large-mouthed pipettes. The embryos were transferred to sealed dishes filled to capacity with embryo solution $(35.4 \mathrm{mM} \mathrm{NaCl}, 2 \mathrm{mM} \mathrm{CaCl}$, and $0.5 \mathrm{mM} \mathrm{KCl}$ buffered to $\mathrm{pH} 6.7$ with $5 \mathrm{mM}$ piperazine- $N, N^{\prime}$-bis $(2$ ethanesulfonic acid)). The embryo solution was changed daily until the embryos hatched from their egg cases 13 to 14 days after egg laying. Hatched embryos were transferred to covered dishes filled with normal $H$. ghilianii water. Embryos were raised at $21^{\circ}$ or $27^{\circ} \mathrm{C}$. At the lower temperature leeches develop more slowly but apparently normally. Embryos are staged by a set of external morphological characteristics correlated with each day of development at $27^{\circ} \mathrm{C}$ (unpublished data).

Dissection. Embryos 11 to 16 days old were pinned out, dorsal side up, in a Sylgard-lined dish filled with cold $H$. ghilianii saline $(130 \mathrm{mM} \mathrm{NaCl}, 4$ or sometimes $8 \mathrm{mM}$ $\mathrm{KCl}, 1.8 \mathrm{mM} \mathrm{CaCl}_{2}, 1.8 \mathrm{mM} \mathrm{MgSO}_{4}$, and $10 \mathrm{mM}$ HEPES buffer, $\mathrm{pH}$ 7.6). A longitudinal cut was made on the dorsal surface and the yolk was carefully blown away with a mouth pipette. The yolky saline was replaced by fresh saline and the central nervous system (CNS) was exposed by making a cut in the celomic membrane lying just dorsal to it. Embryos were unpinned and transferred to a recording chamber. Sometimes, older embryos (14 days and older) were repinned ventral side up in the dissection dish after exposing the CNS dorsally. A small midline tear was made with fine forceps in the embryo and a midline cut was made to expose the CNS ventrally as well.

Physiology and anatomy. The recording chamber was constructed from a $3 \times 1$ inch, $1.2-\mathrm{mm}$-thick slide. A moat was cut around a rectangular island of glass in the middle of the slide with a small grinding tool. The moat was then filled with Sylgard or wax and a rubber O-ring was glued on the slide to hold the saline which immersed the embryo during experiments. Embryos were pinned out either dorsal or ventral side up in the recording chamber so that the CNS laid over the center island of glass.

The recording chamber was secured on the stage of a modified compound microscope outfitted with Nomarski interference contrast optics for visualization of individual neurons and epi-illumination for visualization of cells filled with fluorescent dye. Intracellular recording and stimulation were made by impaling cells with glass microelectrodes filled with $0.2 \mathrm{M} \mathrm{KCl}$ (200 to 400 megohms). Low amounts of current (less than $0.5 \mathrm{nA}$ ) were passed into penetrated cells via a standard bridge circuit. Intracellular ionotophoretic dye injections were made with microelectrodes filled with 3 to $10 \%$ Lucifer Yellow dye (Stewart, 1978). Lucifer Yellow-filled cells were photographed in the living embryo and reconstructed from photographic slides. To stain neurons with horseradish peroxidase (HRP), HRP was pressure-injected into neuron cell bodies and allowed to diffuse for $24 \mathrm{hr}$ while the preparation was incubated at $16^{\circ} \mathrm{C}$ in invertebrate culture medium (Sato's medium plus $5 \%$ horse serum and $25 \%$ calf serum). The preparation was fixed in $8 \%$ glutaraldehyde for 1 to $2 \mathrm{hr}$ at $4^{\circ} \mathrm{C}$, rinsed $30 \mathrm{~min}$ in $0.1 \mathrm{M}$ sodium cacodylate and $1 \mathrm{~min}$ in $8 \%$ sucrose, and placed in saturated benzidine solution for $15 \mathrm{~min}$. The reaction was started by adding 10 to $20 \mu \mathrm{l}$ of $0.3 \% \mathrm{H}_{2} \mathrm{O}_{2} / 10 \mathrm{ml}$ of benzidine solution. After 5 to $15 \mathrm{~min}$ the reaction was stopped by briefly rinsing in $8 \%$ sucrose followed by cold $15 \%$ sodium nitroferricyanide for $10 \mathrm{~min}$. The preparation was dehydrated in absolute ethanol ( $5 \mathrm{~min}$ ), cleared in xylene ( $2 \mathrm{~min})$, and mounted in Permount. Sectioned embryonic nerve cords were prepared according to the method of S. Kim and D. K. Stuart (personal communication). Whole embryos were fixed in $10 \%$ formalin for several days and embedded in glycol methacrylate. Horizontal sections $2 \mu \mathrm{m}$ thick were cut on a JB- 4 microtome (Sorvall) and stained with methylene blue and basic fuchsin.

\section{Results}

\section{Development of the nervous system}

The embryonic stages of neural development. Early development of the glossiphoniid leech has been described by Fernandez (1980), Fernandez and Stent (1980), and Weisblat et al. (1980a, b). During the first eight stages of development, the uncleaved yolk-filled egg, which initially is $2 \mathrm{~mm}$ in diameter, is transformed via a series of well defined cell divisions into a narrow germinal plate that lies over the yolk along the future ventral midline of the body (Fig. 1). The nervous system, skin, muscles, and other ectodermal and mesodermal organs of the leech arise from this germinal plate. The ventral nerve cord forms along the midline of the germinal plate. As the embryo matures, the germinal plate elongates and expands laterally around the circumference of the embryo until its leading edges meet on the dorsal midline and fuse, enclosing the yolk within a body cavity. Although the dorsum of the embryo is not covered by the germinal plate until this body closure, the ectodermal and mesodermal structures of the dorsal body wall are already present and developing in the germinal plate when it is only a narrow strip on the ventral midline. On either side of the midline of the germinal plate, there is a hematoxylin-staining line midway between the ventral midline and the leading edge of the germinal plate that bisects each side of the germinal plate (R. S. Sawyer, personal communication). The germinal plate tissue lateral to these lines will become part 


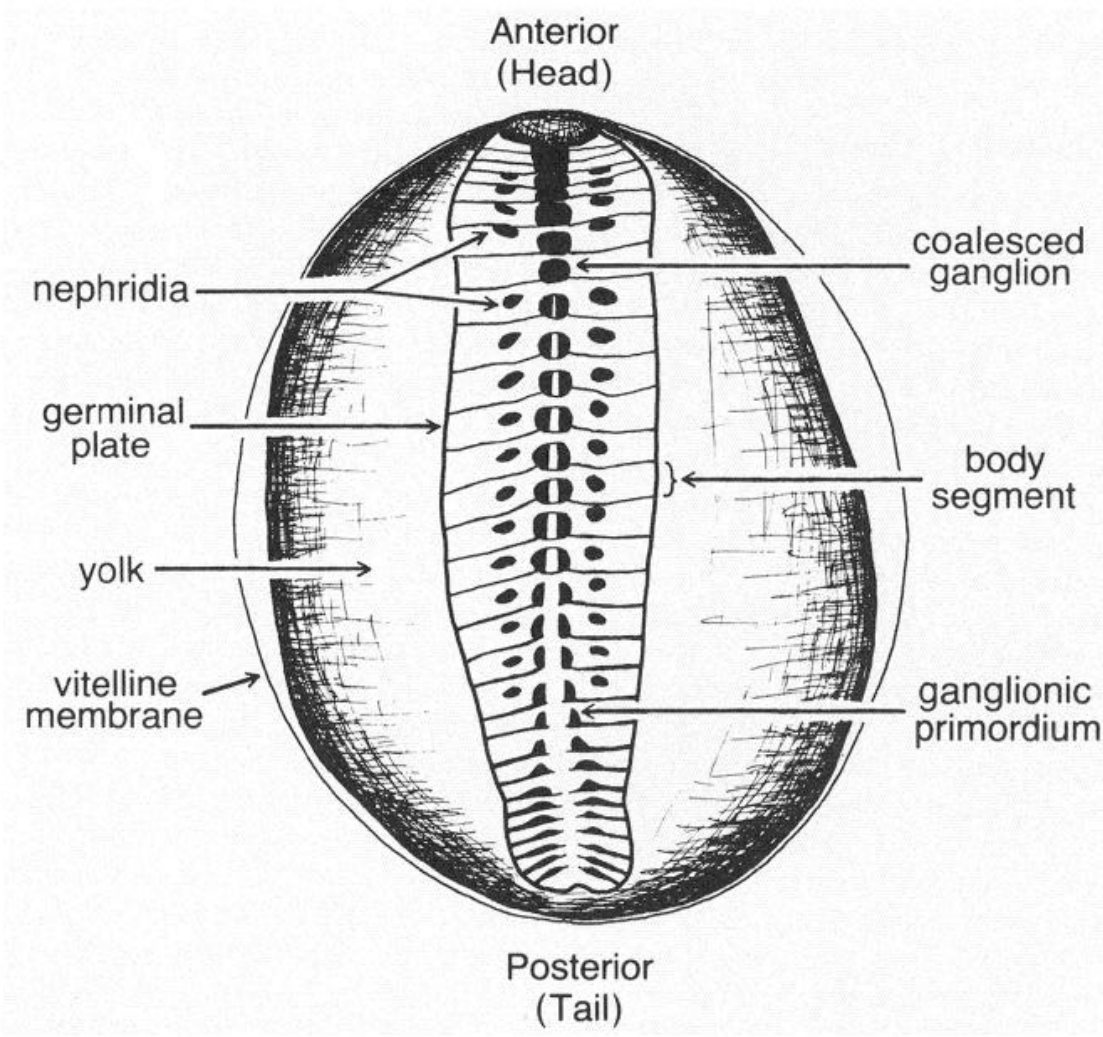

Figure 1. Drawing of a $H$. ghilianii embryo at middle stage 9 . The embryo is 2 to $2.5 \mathrm{~mm}$ long.

of the dorsal body wall and skin (and thus is termed dorsal germinal plate), and tissue medial to the lines will become ventral body wall and skin (and is termed ventral germinal plate). Because the germinal plate expands laterally by growing uniformly along its width, the hematoxylin-staining lines eventually lie at the lateral edges of the body, which delineate dorsum and venter.

Stage 9 of development begins with completion of the formation of the germinal plate. During this stage, the germinal plate becomes partitioned into a series of tissue blocks that correspond to the future body segments. Segmentation begins anteriorly and gradually progresses to the posterior of the embryo. By the time segmentation is complete, the embryo has hatched from the vitelline membrane. Stage 10 begins with completion of the formation of the 32 ventral nerve cord ganglia. During stage 10 the germinal plate continues expanding circumferentially until body closure is attained. Stage 11 begins with completion of body closure. During stage 11, the digestive system matures, as do the skin and muscles of the leech body wall. Stage 11 ends with exhaustion of yolk, at which time embryos become juveniles that have the adult form and are capable of feeding. Thus $H$. ghilianii embryos grow directly into the adult phenotype without passing through a larval stage.

The duration of stage 9 for $H$. ghilianii raised at $27^{\circ} \mathrm{C}$ is 4 days, the duration of stage 10 is 5 days, and that of stage 11 is 20 days. Each day of development is designated by giving the stage number of the embryo followed in parentheses by the number of days completed since the start of the stage divided by the normal duration in days of that stage. Thus a $H$. ghilianii embryo that has developed for 2 days at $27^{\circ} \mathrm{C}$ after reaching stage 9 is at stage $9(2 / 4)$.

More than 100 embryos between stages $9(0 / 4)$ and $11(4 / 20)$ were utilized to reconstruct the embryonic development of $H$. ghilianii. Our description of the morphological and physiological development of the pressure sensory neurons, described later, are based on dye fills from 248 neurons and intracellular records from 48 neurons, respectively. Descriptions of embryonic touch-sensitive neurons are based on more than 20 dye-filled neurons and annulus erector (AE) motor neurons from 10 dye fills.

Gangliogenesis. The nervous system follows an anterior-posterior progression of development, as does the rest of the embryo (Fig. 1). Late in stage 8 , the ventral nerve cord appears in anterior segments as segmental clusters of cells on either side of the ventral midline. At first separated by a midline gap, these ganglionic primordia coalesce on the ventral midline to form globular ganglia. When first formed, these ganglia are juxtaposed but unconnected, except by the connective muscle cells (see below). Later they become connected to each other by a paired lateral connective nerve and an unpaired midline Faivre's nerve which are ensheathed along with the connective muscle cells to form the interganglionic connectives. Then as the embryo elongates, the middle 21 ganglia move apart. The first four ganglia and the last seven ganglia remain unseparated and fuse to form the subesophageal ganglion of the head and the caudal ganglion of the tail. The supraesophageal ganglion has a different embryonic origin (Weisblat et al., 1980a).

At stage $9(0 / 4)$ only the frontmost four ganglia of the 
nerve cord have been formed, and in the midbody region, but not at the rear of the germinal plate, paired ganglionic primordia are present. At stage $9(1 / 4)$, ganglia are present in the anterior half of the embryo and primordia have appeared at the rear except in the tail region (Fig. 1). By stage 9(2/4) ganglia are present everywhere except in the tail region, where they do not become completely coalesced until stage $10(0 / 5)$. At stage $9(2 / 4)$ the midbody ganglia are clearly separated and joined by short connectives.

The ganglionic primordia appear to consist mainly of undifferentiated nerve cell bodies. The neurons initially are all roughly about the same size ( 5 to $7 \mu \mathrm{m}$; Fig. $2 A$ ). As they begin to extend neurites during subsequent development, the cell bodies of some neurons grow larger in diameter much faster than others. The cell bodies of the $\mathrm{P}$ mechanosensory neurons, which we study in detail below, are among the first to become distinctively large (Fig. $3 A$ ) - at stage $9(3 / 4)$ they are among the largest cell bodies in the ganglion. Yet by stage 11, other cell bodies have surpassed them in size, and in the adult there are several other cell bodies in the ganglion that are larger (Fig. 3B; Kramer and Goldman, 1981).

Shortly after coalescing on the ventral midline (by stage $9(2 / 4)$ ), cells of the ganglion are distinctly subdivided into three bilateral clusters: an anterior, middle, and posterior cluster (Figs. $2 B$ and $3 A$ ). These ganglion clusters do not correspond to the six cell packets of the adult ganglion (Coggeshall and Fawcett, 1964; Macagno, 1980). The packets are formed later, during stage 10 , when the ganglion becomes subdivided presumably by the six packet glia cells and connective tissue (e.g., Fig. $3 B$ ). The anterior ganglion cluster appears to be incorporated into the paired anterior lateral and the unpaired medial anterior cell packets; middle and posterior ganglion clusters appear to be incorporated into the paired posterior lateral and the unpaired medial posterior cell packets.

The connective muscle cells lie in the space between early ganglia before connective nerve tracts are formed (Fig. 2A). There are two pairs of these cells per segment, a medial and a lateral pair. Cell lineage tracing has shown
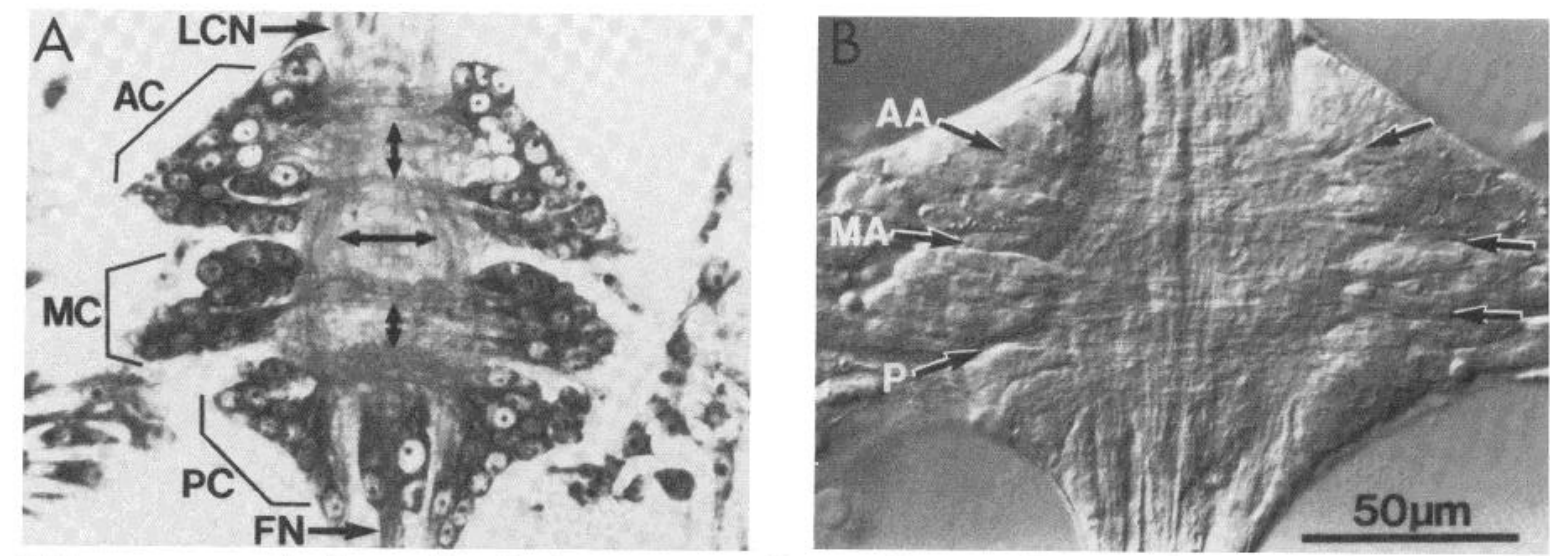

Figure 2. Nerve tracts and cell groupings in the stage 9 ganglion. A, Horizontal section through the dorsal half of a ganglion at stage $9(1.5 / 4) . A C, M C$, and $P C$, anterior, middle, and posterior lateral cell clusters; $L C N$, lateral connective nerve tract; $F N$, Faivre's nerve tract. Four dorsal commissural tracts are indicated with double-headed vertical arrows. Longitudinal nerve tracts are indicated with a double-headed horizontal arrow. B, Nomarski photomicrograph of a stage $9(3 / 4)$ ganglion focused at the same level as the section in A. Arrows indicate points of origin of the three peripheral nerves, which are somewhat out of focus at this level.
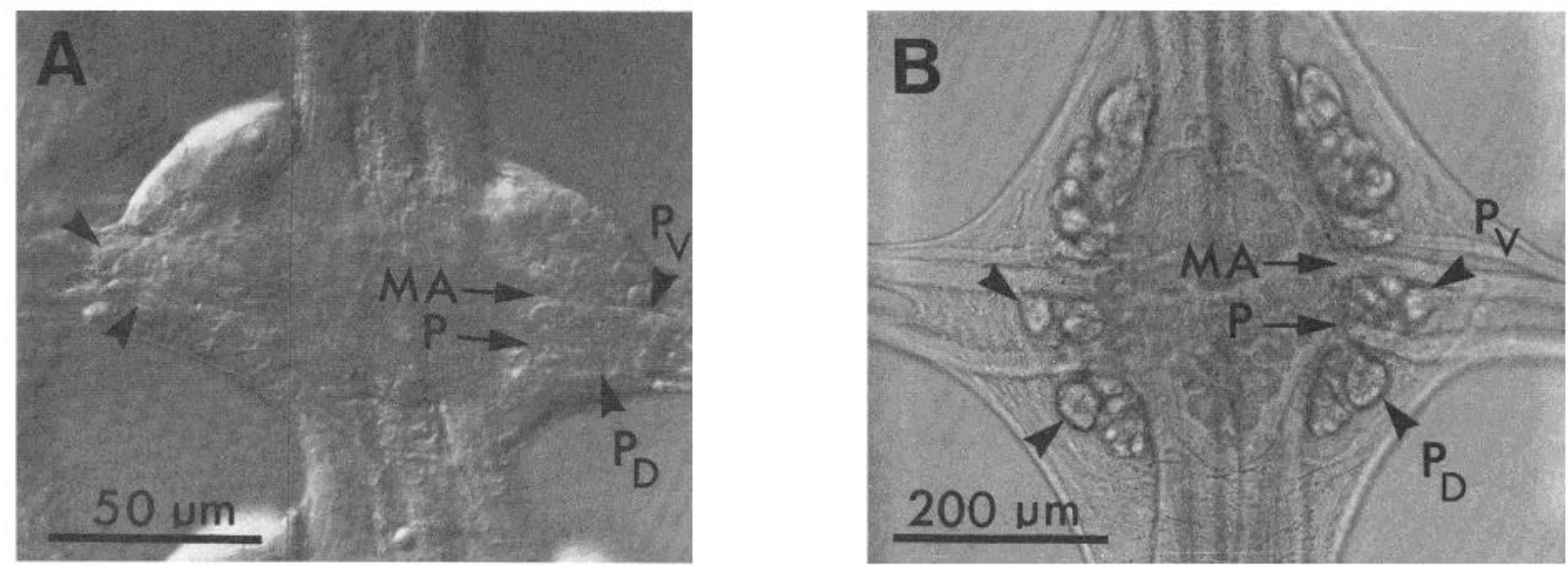

Figure 3. Characteristic location and relatively large size of the $\mathrm{P}$ neuronal somata. $A$, Ganglion from a stage $10(0 / 5)$ embryo. $B$, Ganglion from a small adult leech. The arrowheads point to the cell bodies of the $\mathrm{P}$ neurons and the arrows denote the central continuations of the MA (medial anterior) and P (posterior) nerves. In both photographs anterior is up. 
that both cell pairs are derived from mesoderm (Weisblat et al., 1980a; D. A. Weisblat et al., personal communication), and they are contractile at very early stages. Medial cells in stage $9(3 / 4)$ embryos will contract when penetrated by a microelectrode and when depolarized by current injections. When they contract, they draw neighboring ganglia toward each other, so that a concerted contraction of the muscles in all segments shortens the whole nerve cord. The medial muscle cells are positioned along the ventral midline as early as stage $9(0 / 4)$ when there are only ganglionic primordia. The lateral muscle cells appear to migrate from the mesodermal tissue block to a position on either side of the medial muscle cells by stage $9(1 / 4)$ (Fig. $2 A$ ). At this stage, both pairs of cells are located dorsal to the ganglia and the muscle cells of adjacent segments join together at their ends (Fig. 4A).

Neurogenesis and the formation of nerve tracts. By injecting embryonic neurons with Lucifer Yellow from late stage 8 onward, we found that many stage $9(0 / 4)$ cell bodies in the dorsal halves of coalesced ganglia have not yet extended any processes. Some sets of neurons without processes are dye coupled. This was most regularly observed for the dorsal cells of the anterior ganglion cluster (in six of six clusters tested), until between stages $9(1 / 4)$ and $9(2 / 4)$, when they were no longer dye coupled and had begun to sprout processes. The pattern of early dye coupling followed by dye uncoupling during process growth is similar to that observed in embryonic grasshopper neurons (Goodman and Spitzer, 1979). In general, dye-filled cells on the dorsal surface of all three ganglion clusters of anterior ganglia had begun to grow many fine processes by stage $9(1 / 4)$. However, a half day to a day later, cells in the same area usually had a single neurite, and it was almost always directed straight toward the midline of the ganglion through the future neuropil. In horizontal sections of a midbody ganglion at stage $9(1.5 /$ 4 ), it is evident that most neurons in the lateral part of the ganglion clusters have extended neuropilar processes which form bundles or tracts (Fig. 2A) that appear to be forerunners of the commissural tracts of the more mature ganglion (Fig. 2B).

Two of the three peripheral nerves that extend from the ganglion originate as nerve tracts in the grooves between the ganglion clusters. The root of the medial anterior (MA) nerve forms between the anterior and middle ganglion clusters, and the posterior nerve root forms between the middle and posterior clusters (Fig. $3 A$ ). The anterior anterior (AA) nerve root forms in the middle of the anterior cluster. In the periphery, the posterior nerve splits into the dorsal posterior (DP) and posterior posterior (PP) nerves. The first neural processes to leave the ganglion at these locations are observed between stages $9(2 / 4)$ and $9(3 / 4)$. The $\mathrm{P}$ mechanosensory neurons, whose development is described in detail below,
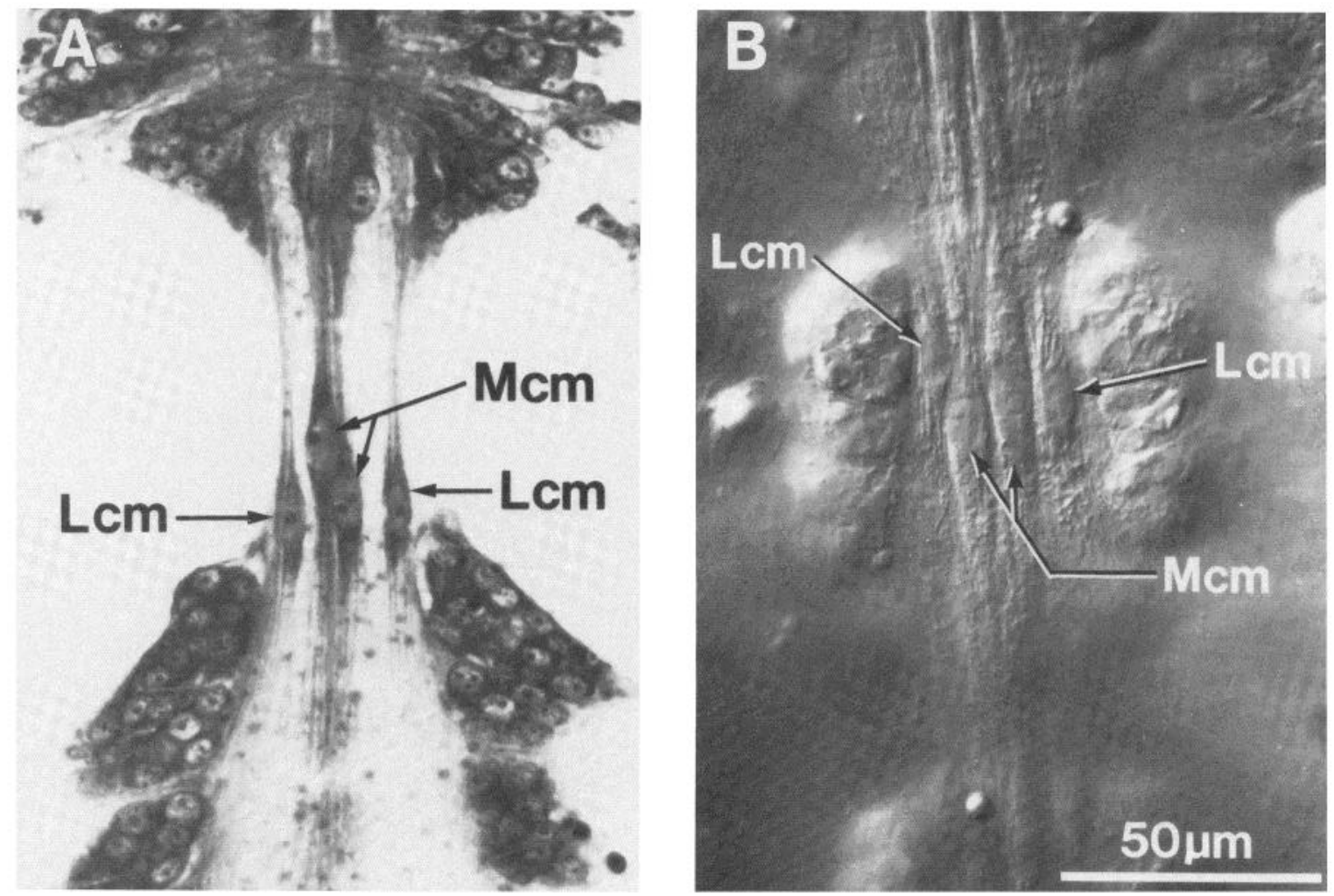

Figure 4. Connective muscle cells. A, Horizontal section through one set of medial $(\mathrm{Mcm})$ and lateral $(\mathrm{Lcm})$ connective muscle cells in a stage $9(1.5 / 4)$ embryo. The section cuts obliquely through most of the connective from the dorsal surface at the bottom ganglion to the ventral surface at the top ganglion. At this stage, ganglia are joined mainly by processes of the connective muscle cells and perhaps some intersegmental axons. $B$, Nomarski photomicrograph of the dorsal surface of a stage $9(2.5 / 4)$ ganglion showing the four connective muscle cells. In both photographs anterior is up. 
are perhaps the first neurons to send processes into the regions of the future medial anterior and posterior peripheral nerves.

\section{Development of pressure mechanosensory neurons}

The leech CNS contains the cell bodies of numerous mechanosensory neurons including the pressure-sensitive or P neurons (Nicholls and Baylor, 1968). There are two pairs of neurons per ganglion in $H$. ghilianii: the ventral $\mathbf{P}$ neuron $\left(\mathrm{P}_{\mathrm{V}}\right)$ primarily innervates the ventral skin and the dorsal $\mathrm{P}$ neuron $\left(\mathrm{P}_{\mathrm{D}}\right)$ innervates dorsal and some of the ventral skin (Kramer and Goldman, 1981). The morphology of mature $P$ neurons can be seen in Figure 5. Both neurons send axons to the periphery from their own ganglion and from adjacent anterior and posterior ganglia. Axons exiting the ganglion containing the cell body, the segmental ganglion, give rise to the major receptive field, whereas minor receptive fields arise from axons exiting adjacent ganglia (see Fig. 1 in Kramer and Kuwada, 1983). The major and each minor receptive field is often contributed to by several axons in different peripheral nerves (Fig. 5). The $P_{D}$ neuron always has an axon in the DP and MA nerves of each ganglion and sometimes has an axon in the PP and AA nerves. The $\mathrm{DP}$ axon innervates dorsal skin and the MA, PP, and AA axons innervate ventral skin (see Fig. 1, Kramer and Kuwada, 1983). The $P_{V}$ neuron always has an axon in the MA nerve and occasionally one in the PP nerve (A.
P. Kramer and J. R. Goldman, manuscript in preparation).

Morphological development of $P$ neurons. In juvenile and adult leeches, the $\mathbf{P}$ neurons are readily identifiable: $P_{D}$ is lateral and just posterior to the central tract of the posterior nerve, and $\mathrm{P}_{\mathrm{V}}$ is lateral and just posterior to the central tract of the MA nerve (Fig. $3 B$ ). In embryos the $\mathrm{P}$ neurons can be unambiguously identified in midbody ganglia 8 to 16 at stages $9(3 / 4)$ to $10(0 / 5)$ on the basis of a unique morphology, larger cell body size, and characteristic cell body location. The $P_{D}$ neuron can be found in the posterior ganglion cluster just posterior to the primordial root of the posterior nerve, and the $P_{V}$ neuron is found in the middle ganglion cluster just posterior to the primordial root of the MA nerve (Fig. $3 A$ ). At stages $9(1 / 4)$ and $9(2 / 4)$, two distinctively large cells can be found in the same location: these presumably are the $P_{D}$ and $P_{V}$ neurons.

As in the case of the other laterally located neurons that were surveyed (see previous section), central processes are the first distinct neurites (processes that grow directly from the cell body) to begin growing from the $\mathrm{P}$ neurons. In stage 9(1/4) embryos the $P_{D}$ neuron from a midbody ganglion has a medially directed growth cone, with numerous very fine unbranched processes (less than $0.25 \mu \mathrm{m}$ in diameter) which presumably are filopodia (Figs. $6 A$ and $7 A$ ). A half-day later, the growth cone has branched to give rise to anterior and posterior growing processes (Fig. $6 B$ ). By stage $9(2 / 4)$ the central processes

A.

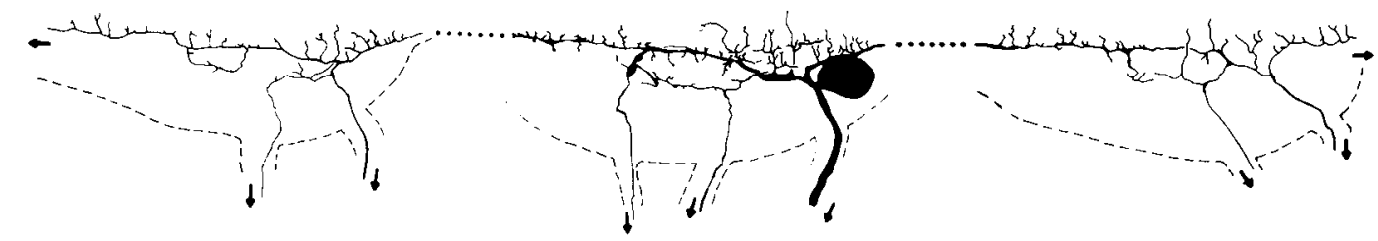

AA MA P

B.
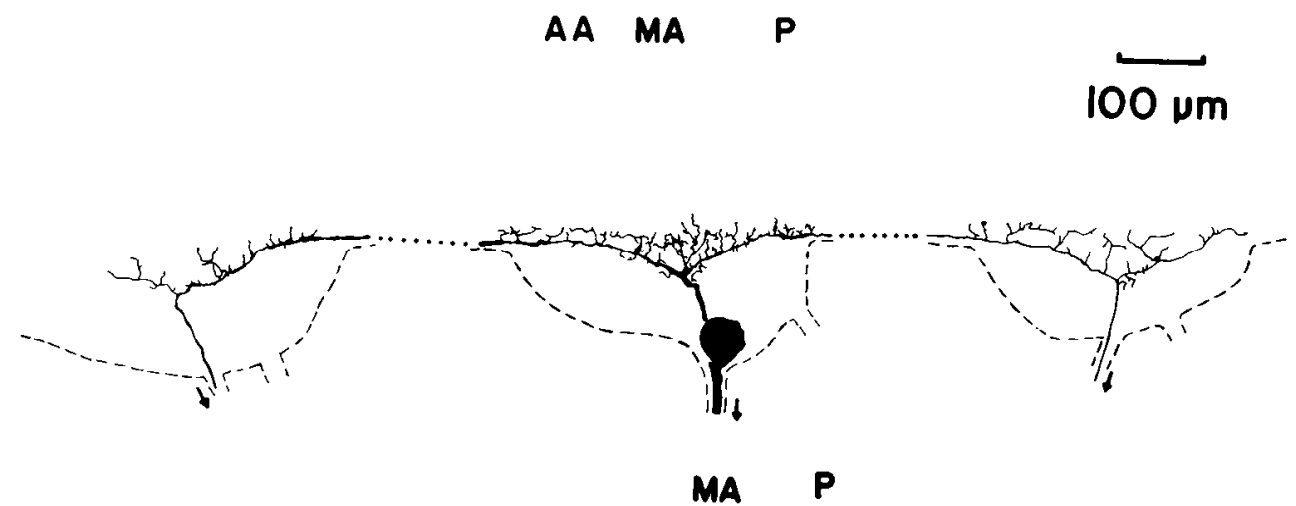

Figure 5. The morphology of $\mathrm{P}$ neurons from adult leeches. The central and peripheral processes in three successive midbody ganglia are shown. $A, \mathrm{P}_{\mathrm{D}}$ neuron with soma in ganglion $13 . B, \mathrm{P}_{\mathrm{v}}$ neuron with soma in ganglion 10 . These cells were injected with HRP and reconstructed with a camera lucida. Dots denote that the central axons are continuous and arrows show that the axons continue beyond the limits of the reconstructions. The central axons of the $P_{D}$ neuron extended to the next ganglia. The MA (medial anterior) and P (posterior) nerves are indicated in each ganglion except in ganglion 13 where the AA (anterior anterior) nerve is drawn as well. Dashed lines indicate the outline of ganglia. In this figure and all succeeding ones through Figure 11, anterior is to the left and medial is up. 
A B. c.

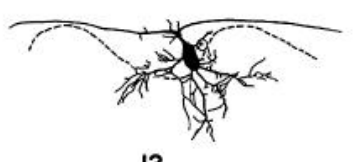

12

D.

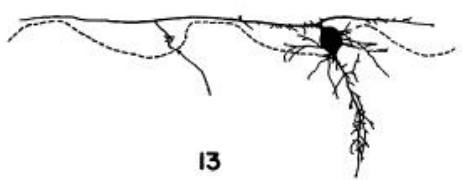

E.

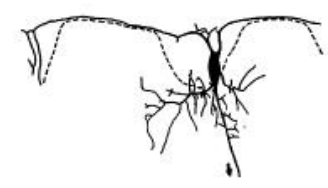

14

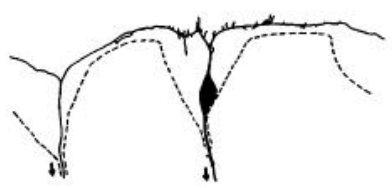

15

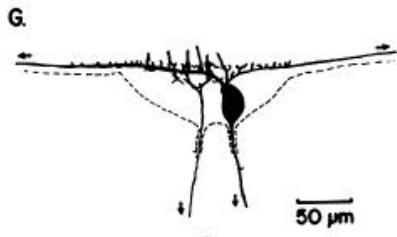

18

Figure 6. The morphology of developing $\mathrm{P}_{\mathrm{D}}$ neurons from midbody ganglia 8 to 16. $A$, Stage $9(1 / 4) ;$, Stage $9(1.5 / 4) ; C$, Stage $9(2 / 4) ; D$, Stage $9(3 / 4) ; E$, Stage $10(0 /$ $5) ; F$, Stage $10(1 / 5) ; G$, Stage $10(4 / 5)$. Numbers denote days at $27^{\circ} \mathrm{C}$ since the eggs were laid.
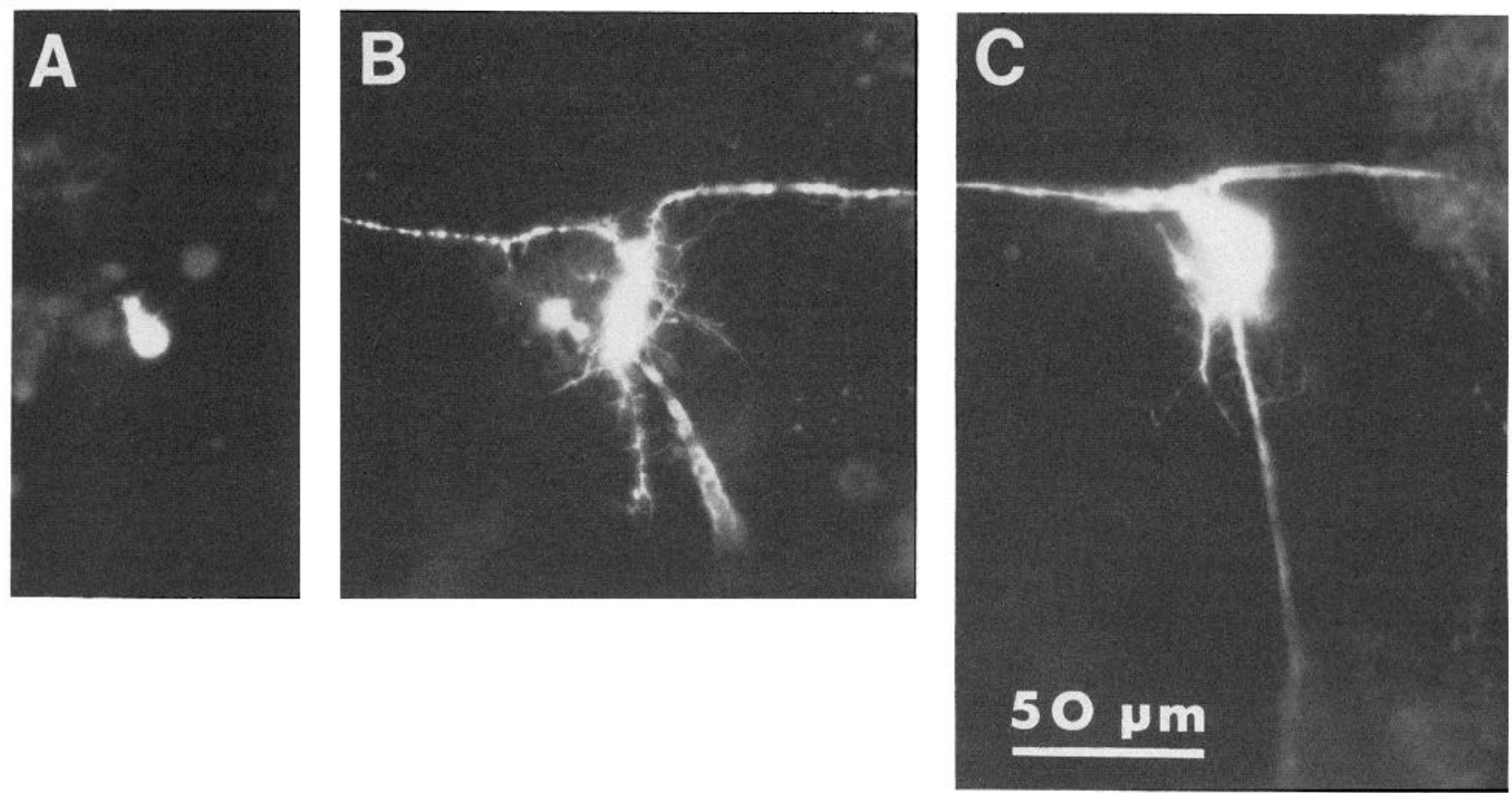

Figure 7. Photographs of embryonic Lucifer Yellow-filled $P_{D}$ neurons from midbody ganglia demonstrating the change from no peripheral process to several processes and perisomatic filopodia, to one primary peripheral axon. $A$, Stage $9(1 / 4) ; B$, Stage $9(2 / 4) ; C$, Stage 9(3/4). Note that some of the processes appear broader than they are because they are out of the plane of focus.

have grown into the ipsilateral connective nerve tracts, which are quite short, to reach the adjacent ganglia. Simultaneously, perisomatic filopodia (filopodia emanating from the soma) and several peripherally directed neurites up to $50 \mu \mathrm{m}$ in length and tipped with growth cones and filopodia have emerged onto the ventral germinal plate neighboring the ganglion (Figs. $6 C$ and $7 B$ ). At this time peripheral nerves are not yet evident.

Soon after stage $9(2 / 4)$ one neurite of the $P_{D}$ neuron is often clearly longer and its growth cone broader than the others. By stage $9(3 / 4)$ this neurite has grown in a posterior and lateral direction to the dorsal germinal plate (Figs. $6 D$ and $7 C$ ). This process is the first or primary peripheral axon of the $\mathrm{P}_{\mathrm{D}}$ neuron to be estab- lished and grows along mesodermal cells (Kuwada, 1982; J. Y. Kuwada and D. A. Weisblat, unpublished results) and migrating ectodermal cells (D. A. Weisblat and J. Glover, personal communication). In the adult this primary axons is found in the DP nerve which is embedded in a set of dorsoventral flattener muscles. The other peripheral neurites, which will eventually disappear (see below), are relatively shorter and confined to the ventral germinal plate (Figs. $6 D$ and $7 C$ ). The central processes have extended in some cases into the connectives beyond the adjacent ganglia, and often a peripheral axon has begun to develop in the anterior ganglion while the posterior one has not (Fig. $6 D$ ). The anterior processes tend to develop faster than the posterior ones, mirroring 
the anterior-posterior gradient of development displayed by the entire embryo.

By stage 10(0/5) most of the perisomatic filopodia are gone, but often there remain one or two of the shorter, ventral neurites. These neurites can ramify in the ventral germinal plate (Fig. $6 E$ ) while the primary DP axon has begun to branch in the dorsal germinal plate (Kuwada, 1982; see Fig. $2 A$ in Kramer and Kuwada, 1983). In some cases the primary axon has extended a ventral-posterior branch that will become the PP axon. In these cases, the $\mathrm{PP}$ axun is probably a newly grown process distinct from the ventral neurites inasmuch as the PP axon branches off the primary axon, while the ventral axons come off the cell body and, often, both the PP axon and the ventral neurites can be seen in the same neuron. In the CNS, incipient neuropilar processes appear, the future MA axon which will eventually innervate ventral skin buds off the central axon, and central axons often extend two ganglia in each direction. The central processes two ganglia away from the soma persist to adulthood $(n=$ 14, Fig. $5 A$ ).

In the next 2 days the remaining ventral neurites disappear, neuropilar processes will elongate and increase in number, and the peripheral axons from adjacent ganglia will grow into DP nerves to innervate the dorsal skin of adjacent segments (Fig. $6 F$ ). By stage $10(4 / 5)$ the $\mathrm{P}_{\mathrm{D}}$ neuron has well developed neuropilar processes, and the MA axon has left the ganglion (Fig. 6G) and grown into the ventral germinal plate. Subsequently, in some cases, an AA axon will grow off the central axon. The MA, PP, and AA axons grow out after the primary DP axon and are called secondary axons. Only the primary axons is formed from an embryonic peripheral neurite; all secondary axons are branches of either the primary or central axons.

The $\mathrm{P}_{\mathrm{V}}$ neuron develops in a manner similar to the $\mathrm{P}_{\mathrm{D}}$ neuron. For example, the central processes begin developing before the peripheral ones (Fig. 8, $A$ and $B$ ); the
A

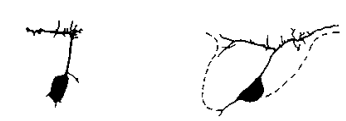

11.5

B

\begin{abstract}
12
\end{abstract}

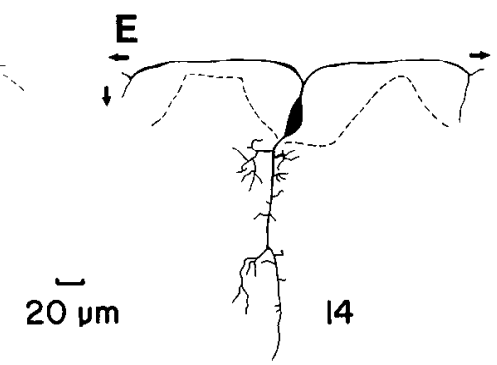

Figure 8. The morphology of developing $\mathrm{P}_{\mathrm{v}}$ neurons from midbody ganglia 8 to 16 . $A$, Stage $9(1.5 / 4) ;$, Stage $9(2 / 4) ; C$, Stage $9(2.5 / 4) ; D$, Stage $9(3 / 4) ; E$, Stage $10(0 / 5)$. In $A, B$, and $C$ the very fine processes coming off the central axons are filopodia. Numbers denote days at $27^{\circ} \mathrm{C}$ since the eggs were laid.
A
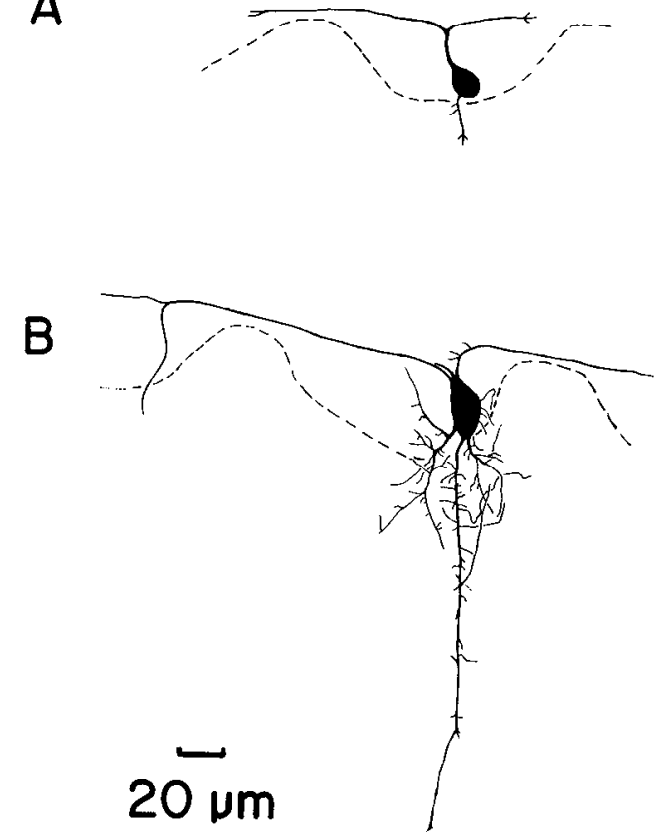

Figure 9. The two $\mathrm{P}$ neurons from the same stage $9(2.5 / 4)$ embryo demonstrating the difference in the rate of process growth between them. $A, \mathrm{P}_{\mathrm{V}}$ neuron from left hemiganglion 8; $B, \mathrm{P}_{\mathrm{D}}$ neuron from right hemiganglion 9 .

peripheral axons are extended in two steps such that the primary peripheral axon (MA) develops first from a neurite followed by occasional growth of a secondary axon ( $\mathrm{PP}$ ) from the central axons, and a single $P_{\mathrm{V}}$ neuron exhibits the same anterior-posterior gradient of development as a $\mathrm{P}_{\mathrm{D}}$ neuron (Fig. $8, C$ and $D$ ). However, there are some exceptions. First, $P_{V}$ normally lags a bit behind $P_{D}$ in development. The $P_{V}$ central axons, especially from stages $9(2 / 4)$ to $10(2 / 5)$, will not be as extensive and the neuropilar processes will not be as developed as those of $\mathrm{P}_{\mathrm{D}}$; also, although both $\mathrm{P}$ neurons project peripheral processes at about the same time (Figs. 6 and 8), the $P_{D}$ primary axon grows much faster than that of the $\mathrm{P}_{\mathrm{V}}$ neuron so that the $P_{D}$ primary axon reaches the dorsal germinal plate before the $P_{V}$ primary axon has arborized much in the ventral germinal plate (Fig. 9). Second, $P_{V}$ establishes its peripheral axon in a manner quite different from that of $\mathrm{P}_{\mathrm{D}}$. Rather than initially projecting numerous neurites, $\mathrm{P}_{\mathrm{V}}$ projects most frequently only a single peripheral neurite which becomes the primary axon by growing laterally from the ganglion at the primordial root of the MA nerve along a path different from that of the $P_{D}$ primary axon. The primary axon subsequently branches and arborizes in the ventral germinal plate (Fig. 8). Thus, early in axonogenesis (middle stage 9 to early stage 10) the peripheral processes of both $P_{V}$ and $P_{D}$ neurons may occupy the ventral germinal plate near the ganglion. The early $\mathrm{P}_{\mathrm{D}}$ processes, however, are eliminated from the ventral plate, whereas the $P_{D}$ primary axon grows directly to the dorsal germinal plate (see above). Third, $\mathrm{P}_{\mathrm{V}}$ neurons from stages $10(0 / 5)$ to $10(2 / 5)$ often have central axons two segments away as the $P_{D}$ neurons have, but they almost always disappear 
before stage 11, except in particular segments. In older embryos and adults, the $P_{v}$ neurons regularly have axons in more than one adjacent segment, only if that segment contains the subesophageal, caudal, or sex ganglia.

The $\mathrm{P}$ neurons, like the dorsal root ganglion cells of the vertebrate spinal cord (Ramon y Cajal, 1960), develop from a bipolar state, with the central axons growing from the medial pole of the cell body and the primary axon from the lateral pole (e.g., Figs. $6 F$ and $8 E$ ), to become monopolar beginning late in stage 10 . In the monopolar state the central and peripheral axons are continuous and attached to the soma by a neurite (Fig. 5).

Lateral and growth cone filopodia. A common feature of many embryonic neurons is the presence of long filopodia projecting from growth cones and of numerous lateral filopodia projecting off the length of processes (Ramon y Cajal, 1960). These filopodia are observed on the central processes of the $P$ neurons from the time of initial growth cone extension to about stage $9(3 / 4)$ for the $\mathrm{P}_{\mathrm{V}}$ neuron and slightly earlier for the $\mathrm{P}_{\mathrm{D}}$ neuron (Fig. $10 A)$. The lateral filopodia can be up to $10 \mu \mathrm{m}$ long and

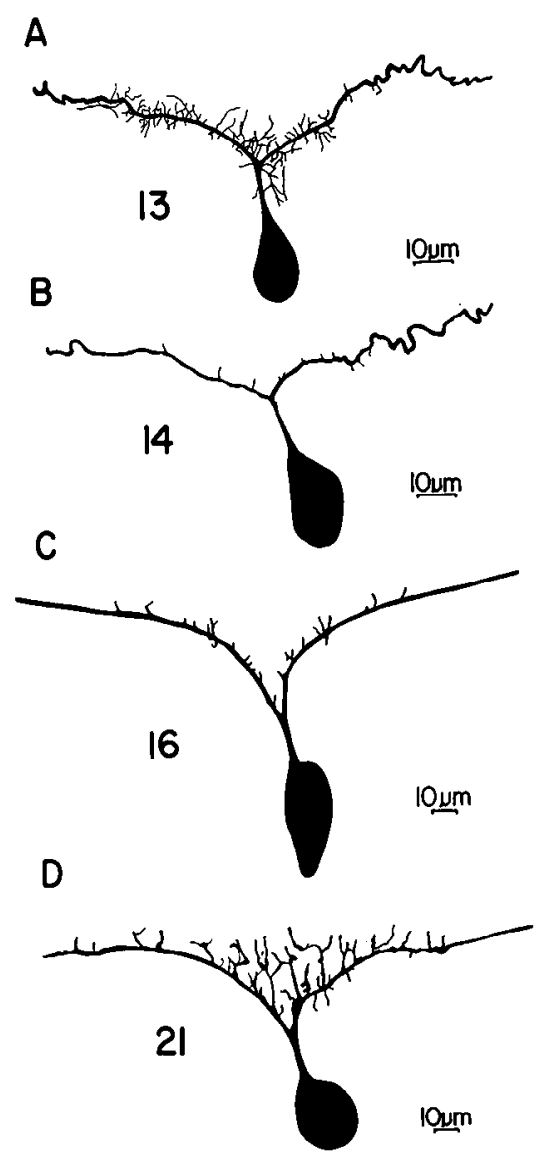

Figure 10. Neuropilar processes are not formed by the selective retention and enlargement of early lateral filopodia. The $\mathrm{P}_{\mathrm{v}}$ neurons from midbody ganglia were reconstructed from slides taken at high magnification to show the lateral filopodia clearly. $A$, Lateral filopodia cover the central axons at stage $9(3 / 4)$. $B$, At stage $10(0 / 5)$ lateral filopodia are nearly all gone. $C$, At stage $10(2 / 5)$ some thicker neuropilar processes appear. $D$, Neuropilar processes are quite mature at stage $11(2 / 20)$. Numbers denote days at $27^{\circ} \mathrm{C}$ since the eggs were laid. are found on the central axons both in the ganglion and the connectives. Although many of the lateral filopodia in the ganglion are oriented like neuropilar processes of $P$ neurons, they do not develop into neuropilar processes. There is a time (stage $9(3 / 4)$ for $P_{D}$ and stage $10(0 / 5)$ for $\mathrm{P}_{\mathrm{V}}$ ) when practically all of the lateral filopodia disappear (Fig. 10B) prior to the development of neuropilar processes from the central axons in the ganglion (Fig. $10, C$ and $D$ ).

Both growth cone and lateral filopodia can be found on the developing peripheral axons as well as the central ones. Notably, the growth cones and their filopodia and lateral filopodia are much more prominent on the primary peripheral axons of $\mathrm{P}$ neurons than on the later projecting peripheral axons both from the ganglion containing the somata and adjacent ganglia (Fig. 11).

Physiology of developing pressure-sensitive cells. Embryonic $\mathrm{P}$ neurons, like mature $\mathrm{P}$ neurons, can have resting potentials between -40 and $-60 \mathrm{mV}$. Their input resistance varies from 200 to 500 megohms between stages $9(2 / 4)$ and $10(3 / 5)$. This declines to 100 megohms in 2- to 3-month-old leeches. The first active response to current injection is delayed rectification which can be seen at stage 9(3/4) (Fig. 12A). The next day, 20-mV allor-none potentials can be elicited by depolarizing pulses (Fig. 12B). These probably represent axonal action potentials passively spread to the cell body. By stage $10(1 /$ 5) neurons are capable of generating overshooting action potentials (Fig. $12 C$ ) which much more resemble the action potential of mature $\mathrm{P}$ neurons (Fig. 12E). However, even through the first half of stage 11 , the action potentials are broader than those of the adult (Fig. 12, $D$ and $E$ ). This is especially noticeable if action potentials are evoked repeatedly or if the preparation is bathed in high $\mathrm{Ca}^{2+}$ saline. Not until the juvenile stage do the action potentials of $\mathrm{P}$ neurons not broaden in the presence of high $\mathrm{Ca}^{2+}$.

In adult leeches spontaneous postsynaptic potentials can be readily recorded in the $\mathrm{P}$ neurons. Spontaneous postsynaptic potentials are evident at stages $10(1 / 5)$ to $10(2 / 5)$ of embryonic $\mathrm{P}$ neurons-just when the neuropilar processes are starting to develop (Fig. 12E).

\section{Development of other identified neurons}

Development of the touch mechanosensory neurons. The three touch or $\mathrm{T}$ neurons are another set of identified mechanosensory neurons found in the leech (Nicholls and Baylor, 1968). They extend their peripheral axons from the ganglion apparently along the same pathway taken by the primary axons of the $P$ neurons. The $T_{D}$ neuron, which innervates dorsal skin, takes the same route to the dorsal germinal plate as the $P_{D}$ neuron, and $T_{V}$ and $T_{L}$ neurons which innervate ventral skin and the dorsal and ventral skin adjacent to the lateral edge, respectively, take the same route into the ventral germinal plate as the $P_{V}$ neuron. Although the peripheral axons of $T_{V}$ and $T_{L}$ neurons begin their development along the same route, their pattern of growth is different. The axon of the $T_{\mathrm{V}}$ neuron branches extensively in the ventral germinal plate in a pattern very much like that 

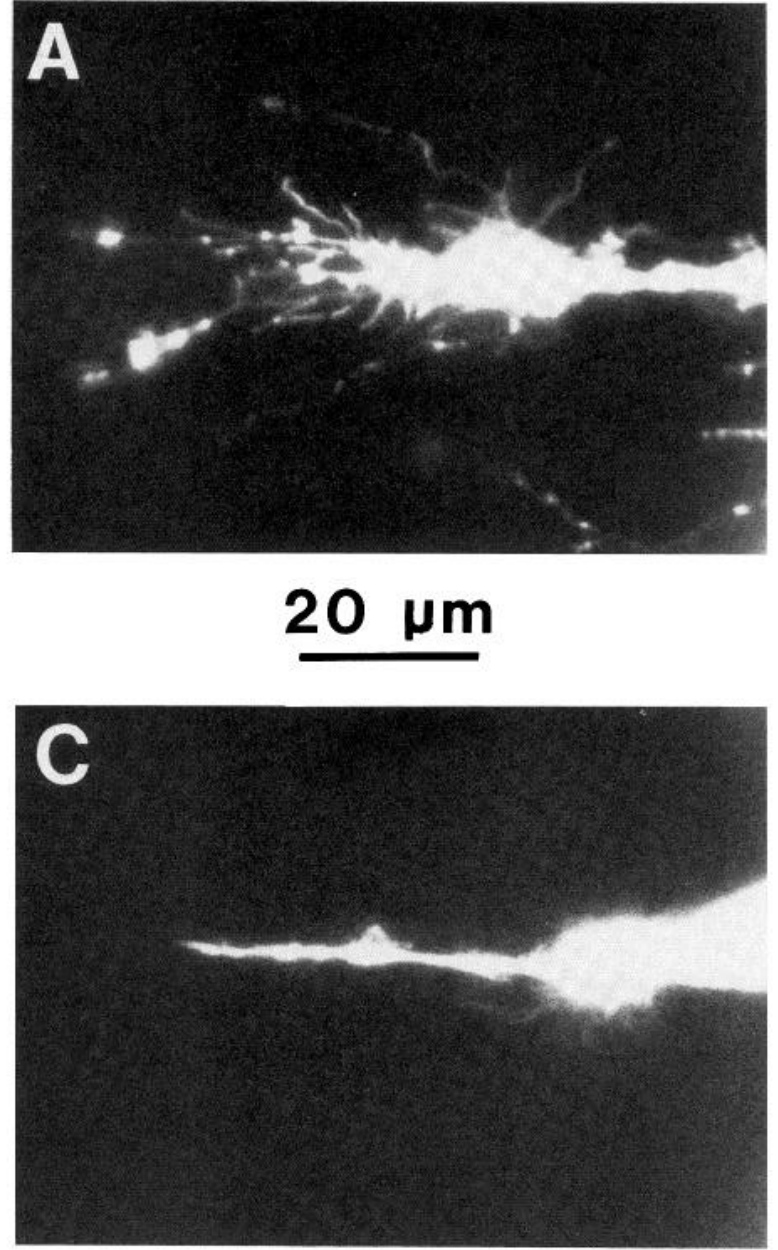
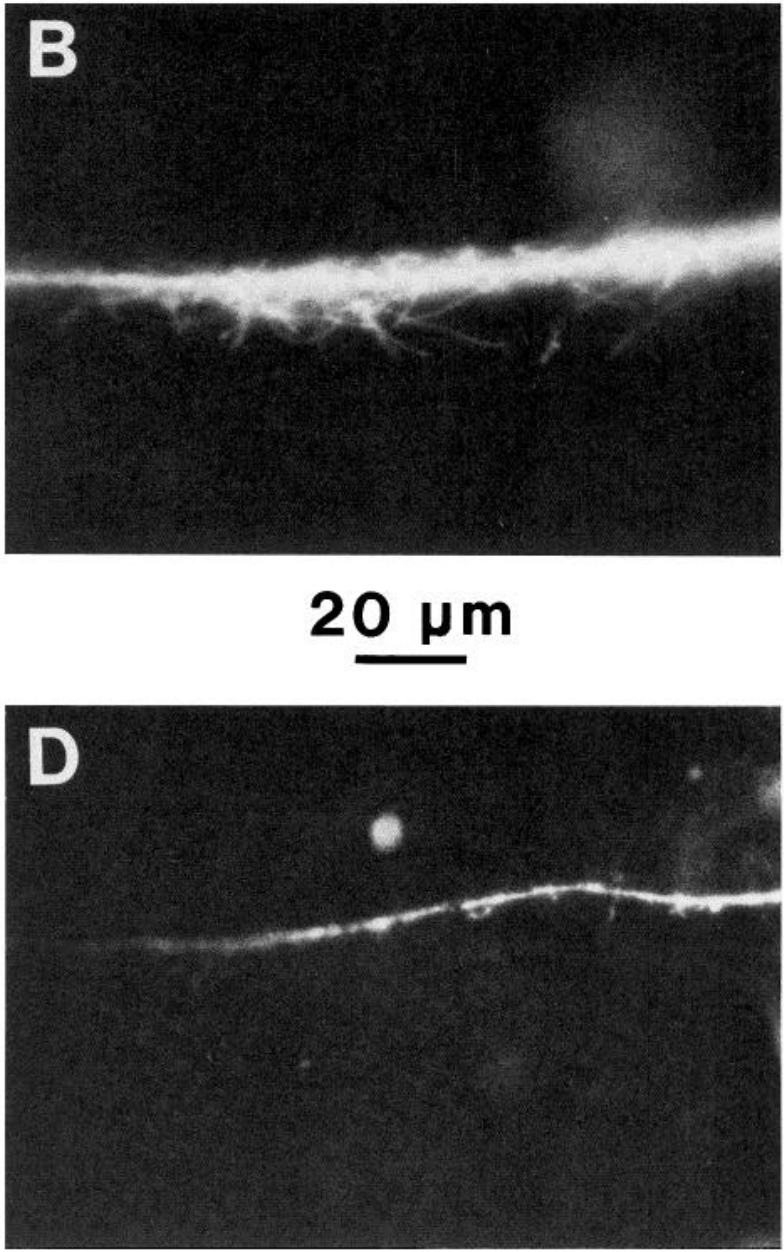

Figure 11. Growth cones and filopodia are prominent on the early primary peripheral axon but not on the later projecting peripheral axons of the $\mathrm{P}$ neurons. $A$, Terminal growth cone and filopodia of the major field primary axon of a stage $10(0 / 5) \mathrm{P}_{\mathrm{V}}$ neuron. $B$, Lateral filopodia projecting off the major field primary axon of a stage $10(0 / 5) \mathrm{P}_{\mathrm{D}}$ neuron. $C$, Bare growth cone of a minor field axon of a stage $10(1 / 5) \mathrm{P}_{\mathrm{V}}$ neuron. The axon behind the growth cone region appears larger than it is because it is out of the focal plane of the photograph. $D$, No lateral filopodia on the thinner minor field axon of a stage $10(0 / 5) P_{D}$ neuron.

of the $\mathrm{P}_{\mathrm{V}}$ neuron, so that by middle stage 10 its branches just reach, but do not cross the future lateral edge of the leech (Fig. 13B). At this same stage, the $\mathrm{T}_{\mathrm{L}}$ neuron has only a few axon branches in the ventral germinal plate and many branches in a narrow territory straddling the future lateral edge (Fig. 13A). Only the branches along the lateral edge occupy the future receptive field of the adult $\mathrm{T}_{\mathrm{L}}$ neuron (Kramer and Goldman, 1981). Thus, presumably at a later stage, the few axon branches in the proximal germinal plate (which are indicated by arrows in Fig. 13A) are lost or do not make receptor endings. The axon field of the $T_{D}$ neuron at this stage occupies only the dorsal germinal plate, between the future lateral edge and the lateral border of the germinal plate (data not shown).

Development of neurons with multiple peripheral axons. The $\mathrm{P}_{\mathrm{D}}$ neuron and occasionally the $\mathrm{P}_{\mathrm{V}}$ neuron project multiple peripheral axons from a ganglion in adult leeches (Fig. 5). As shown in a previous section, both $\mathrm{P}$ neurons initially develop just one peripheral axon, the primary axon. The other peripheral axons or secondary axons emerge later.
Other leech neurons with multiple peripheral axons follow the developmental pattern of the $\mathrm{P}$ mechanosensory neurons by growing first one primary peripheral axon followed by a later outgrowth of secondary axons. The AE motoneuron (Stuart, 1970; Kramer and Goldman, 1981) first extends a process into the contralateral posterior nerve at stage $9(2.5 / 4)$ followed by growth of axons in contralateral MA and AA nerves during stage 10 (Fig. 14). The Retzius cell (Lent, 1973; Kramer and Goldman, 1981) also first extends a process into the posterior nerve, although the ipsilateral one, and this is followed by processes into MA and AA nerves.

\section{Discussion}

This study demonstrates that identified neurons can be investigated in the embryonic leech nervous system with intracellular techniques from the time the first growth cone extends from the cell body. The axon branching pattern of at least some leech neurons develops in a regular way, characterized by the growth of axons along specific pathways toward their targets. 
Timed outgrowth of the axons of the two $\mathrm{P}$ neurons cannot account for the specificity exhibited by their primary peripheral axons for their respective targets. Instead the $\mathrm{P}_{\mathrm{D}}$ neuron appears to demonstrate an early preference for the skin territory which is the target for its primary axon despite an opportunity to innervate the target of the $\mathrm{P}_{\mathrm{V}}$ primary axon. This specific develop-
A

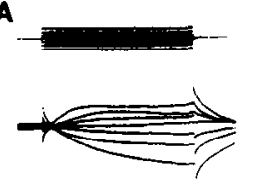

D

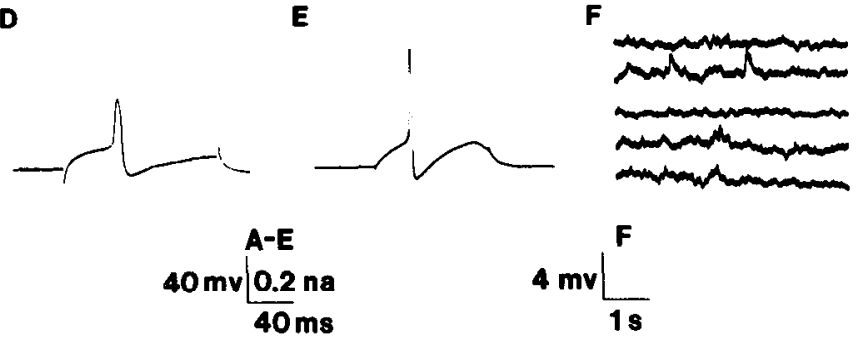

Figure 12. The development of the action potential and the occurrence of spontaneous postsynaptic potentials in $\mathrm{P}$ neurons from midbody ganglia. $A$, Delayed rectification elicited in a stage $9(3 / 4) \mathrm{P}_{D}$ neuron. The current traces are shown above the voltage traces. $B$, The earliest action potential evoked by somatic current injection in a stage $10(0 / 5) P_{D}$ neuron. $C, A n$ overshooting action potential from a stage $10(1 / 5) \mathrm{P}_{D}$ neuron. $D$, A larger and faster action potential from a stage $11(1 / 20)$ $\mathrm{P}_{\mathrm{D}}$ neuron. $E$, An action potential from an adult $\mathrm{P}_{\mathrm{D}}$ neuron. $F$ Spontaneous postsynaptic potentials, both depolarizing and hyperpolarizing, recorded in a stage $10(2 / 5) \mathrm{P}_{\mathrm{v}}$ neuron. The resting potential in $B, C$, and $D$ was $-40 \mathrm{mV}$ and in $E$ was -52 $\mathrm{mV}$. mental pattern is also observed in chick motoneurons (Landmesser, 1978b; Lance-Jones and Landmesser, $1980 \mathrm{a}, \mathrm{b})$ and the earliest developing insect peripheral and central neurons (Bate, 1976; Keshishian, 1980; Bate and Grunewald, 1981; Murphey, 1981; Ho and Goodman, 1982; Raper et al., 1983a, b).

Do $P$ neurons pioneer peripheral nerves? The primary axons of the $\mathrm{P}$ neurons develop when peripheral nerves are not obvious, whereas the secondary axons and peripheral axons in adjacent ganglia develop when those nerves have formed. Several differences are apparent between the growing primary axons and the later developing peripheral axons. The growth cone of the primary axon is broad and flat and covered with long, leading filopodia (up to $40 \mu \mathrm{m}$ ) whereas the growth cones of later developing peripheral axons are tapered and rarely have filopodia. The primary axon is covered with lateral filopidia all along its length whereas the later axons are bare. Additionally, in the case of the $P_{D}$ neuron, the primary axon is established from one of several peripheral processes first projected. The secondary and adjacent ganglion axons develop, from the beginning, from a single process. Presuming that the number of early processes is related to the amount of exploration that precedes primary axon outgrowth, these differences may reflect the difference between growing into the periphery with no other axons to follow versus following other peripheral axons. Therefore, we hypothesize that the primary peripheral axons of $\mathbf{P}$ neurons are some of the earliest peripheral axons to develop and participate in the formation of peripheral nerves. Indeed their cell body locations at the ganglionic roots of peripheral nerves make them well suited for such a role. The later developing axons, however, grow into established nerves to reach their targets.

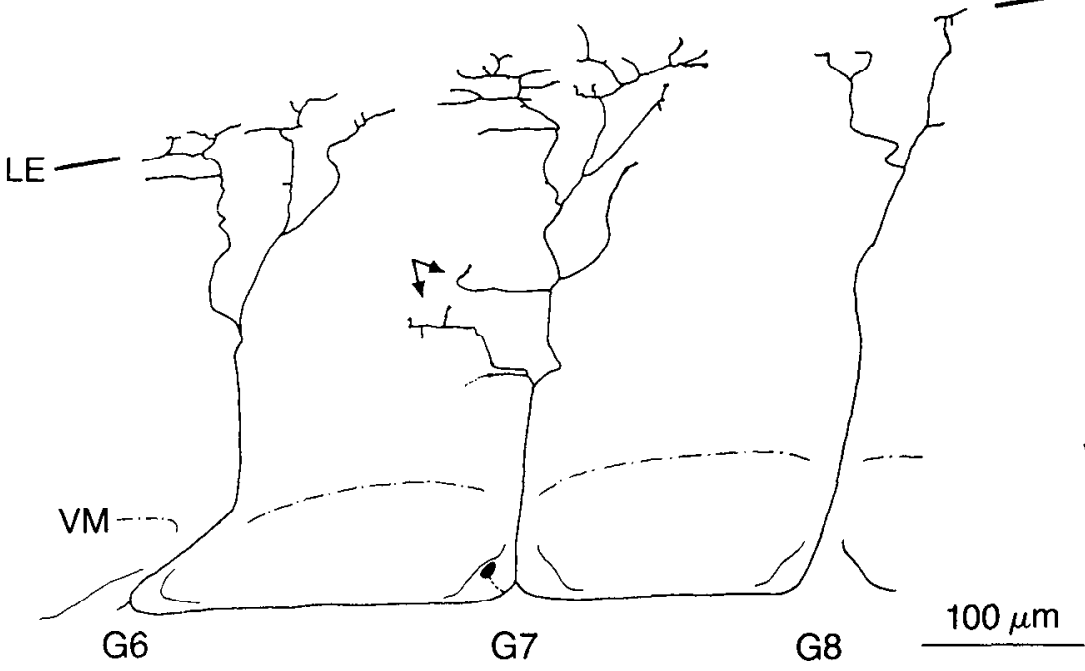

A

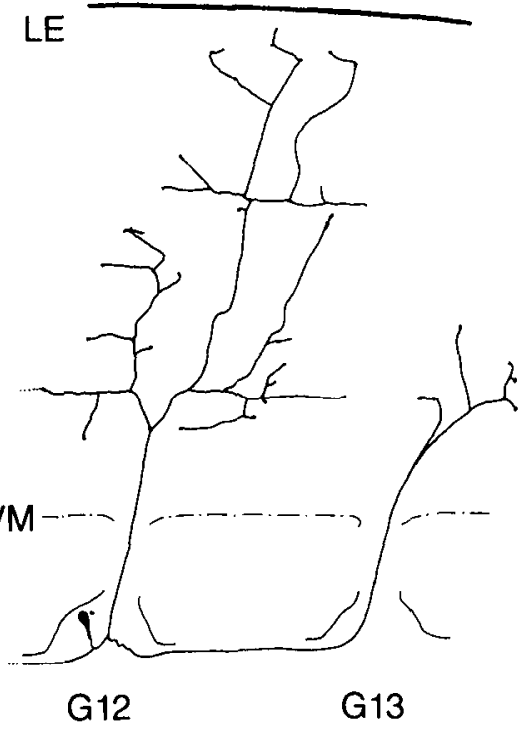

B

Figure 13. The branching pattern of the peripheral axons of embryonic $\mathrm{T}$ neurons, stage $10(2 / 5) . A, \mathrm{~T}_{\mathrm{L}}$ neuron; $B, \mathrm{~T}_{\mathrm{V}}$ neuron. Arrows indicate branches of the $\mathrm{T}_{\mathrm{L}}$ neuron found in the ventral germinal plate which are subsequently lost or do not form functional receptor endings. $L E$, lateral edge; $V M$, ventral midline. 

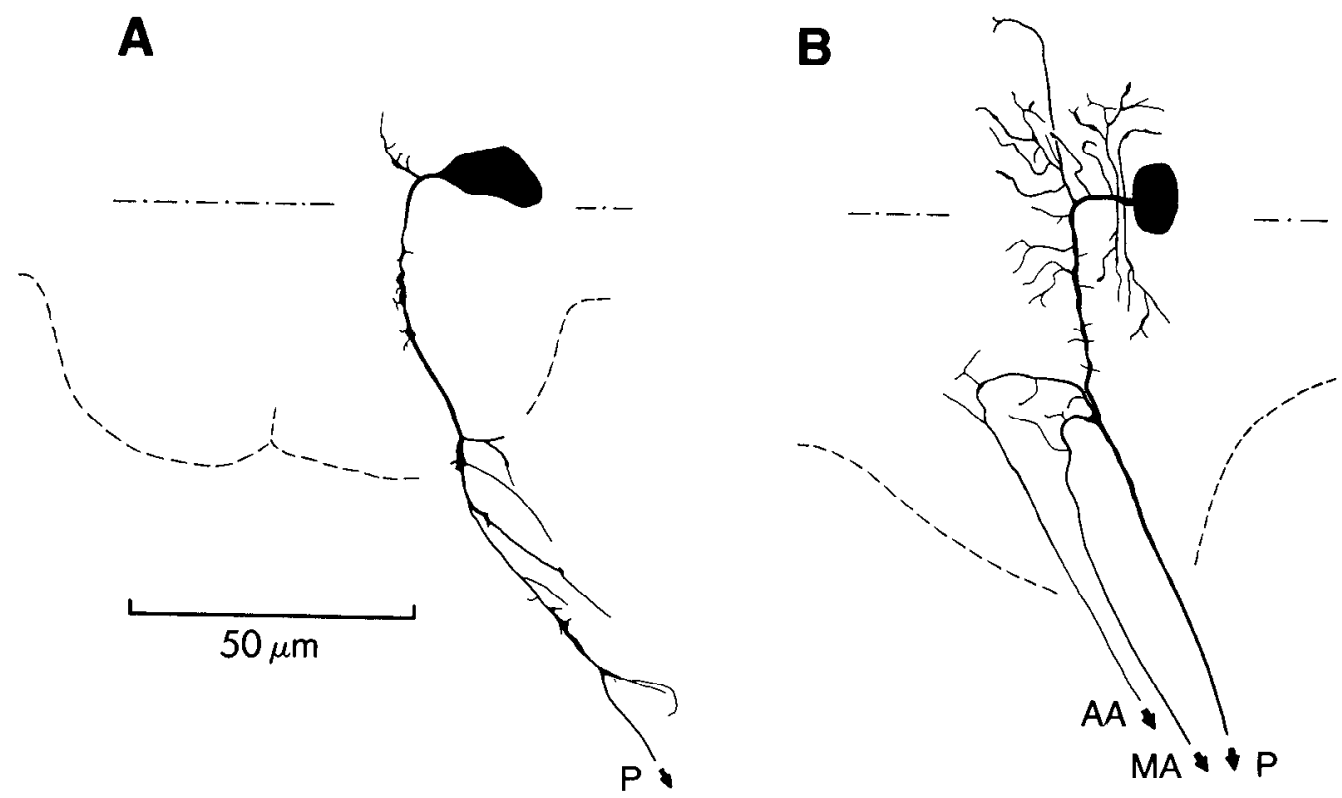

Figure 14. The morphology of embryonic AE motor neurons. $A$, Stage $9(2.5 / 4) ; B$, Stage $10(3 / 5)$.

Specificity of axonal outgrowth. Neurons in the leech CNS, as in many other nervous systems, have unique morphologies, including distinctive axon branching patterns (Muller, et al., 1981). During embryogenesis these axons generally grow in a highly regular and direct fashion. The L motoneuron (J. Y. Kuwada, manuscript in preparation), AE motoneuron, and Retzius cell axons, as well as the axons of the $\mathrm{P}$ neurons, with the exception of the $P_{D}$ primary peripheral axon, are not established by the random outgrowth of processes followed by the retraction of inappropriate ones.

Even the first growth cone of a neuron is direct rather than randomly projected. The first growth cone of $P$ neurons always develops from the medial side of the cell body. This growth cone branches before reaching the midline to give rise to the central axons. It is possible that process outgrowth from the soma is hindered in the anterior and posterior directions by adjacent neuronal somata, but the cells are unapposed in the peripheral and medial directions, yet the first growth cone is always medial.

The formation of the $P_{D}$ primary peripheral axon is the only significant case found so far in the leech of excessive outgrowth of processes followed by pruning. The $P_{D}$ primary axon innervates the dorsal skin, yet during the earliest stages of axonogenesis the $P_{D}$ neuron projects several peripheral processes onto the ventral germinal plate in the vicinity of the ganglion. Simultaneously, the $P_{V}$ neuron, which innervates mainly ventral skin, extends a primary peripheral axon onto the ventral germinal plate as well. Despite this apparent opportunity for the $P_{D}$ neuron to innervate the ventral germinal plate at this time, one of the initial processes develops into the primary axon by growing rapidly along a specific pathway directly to the dorsal germinal plate bypassing the ventral plate. The $\mathrm{P}_{\mathrm{V}}$ axon, however, grows laterally slowly along a different pathway into the ventral germinal plate. The faster growth of the $\mathrm{P}_{\mathrm{D}}$ primary axon allows it to reach its target before the $\mathrm{P}_{\mathrm{V}}$ primary axon has developed much, and the two primary axons begin innervating their respective target tissues at about the same time (Kuwada, 1982; see Fig. $2 A$ in Kramer and Kuwada, 1983). Later, some of the other $P_{D}$ processes may arborize on the ventral plate but these are soon eliminated.

These observations tend to rule out timed outgrowth of axons as a mechanism for the specificity exhibited by the primary axons of $\mathrm{P}$ neurons for their targets. Timed outgrowth has been implicated in the developing arthropod visual system (Anderson, 1978; Macagno, 1978) and would require that the $\mathrm{P}_{\mathrm{V}}$ primary axon grow out before the $P_{D}$ primary axon so that it can innervate the territory near the ganglion (ventral germinal plate), forcing the later growing $P_{D}$ axon to grow farther to find uninnervated territory (dorsal germinal plate). Instead, early in development the $P_{D}$ neuron apparently has an opportunity to innervate the ventral germinal plate, yet it prefers to grow a primary axon to the dorsal plate. This preference is not absolute, since $P_{D}$ secondary peripheral axons will grow out to innervate ventral skin much later. The $\mathrm{T}_{\mathrm{V}}$ and $\mathrm{T}_{\mathrm{L}}$ neurons may also actively seek their respective target areas of the germinal plate. Their peripheral axons grow out along the same pathway, yet by the middle of stage 10 , the $\mathrm{T}_{\mathrm{V}}$ axon has grown to the future lateral edge and arborized extensively in the ventral germinal plate whereas the $T_{L}$ axon has only a few branches in the ventral germinal plate and has arborized mainly along the future lateral edge.

What might be the basis for such a preference displayed by the early $P_{D}$ neuron? The manner in which the $P_{D}$ neuron establishes its primary peripheral axon suggests that the earliest peripheral processes are searching for a cue which can guide a growing process past the ventral germinal plate to the target dorsal germinal plate. When the cue is found by one of the processes, the others are retracted. A cue may be necessary since the dorsal germinal plate is relatively distant (approximately 150 
$\mu \mathrm{m})$ from the $\mathrm{P}_{\mathrm{D}}$ cell body at the time the first peripheral processes are being projected. Unlike the $P_{D}$ neuron, the $\mathrm{P}_{\mathrm{V}}$ neuron cell body lies adjacent to its target. Thus the $P_{V}$ neuron needs only to project a process out of the ganglion to find its target tissue.

Among a number of candidate cues for axonal guidance in the leech are mesodermal cells which appear to be the substrates for growing axons in a number of cases. The pathway taken by the $P_{D}$ primary axon includes mesodermal cells (Kuwada, 1982; J. Y. Kuwada and D. A. Weisblat, unpublished data), some of which probably give rise to the dorsoventral flattener muscles, which in the adult leech embeds the nerve containing the $P_{D}$ primary axon. Also the $\mathrm{P}_{\mathrm{v}}$ peripheral axons and their major branches appear to grow aligned to the circular and longitudinal muscles in the body wall (Kramer and Kuwada, 1983). In the CNS, the four connective muscle cells that connect two successive developing ganglia may be the substrata on which the first intersegmental axons grow. It is possible that, in the leech, mesodermal cells may play a guidance role within the CNS to establish nerve tracts and in the periphery to form peripheral nerves as has been proposed for embryonic grasshopper motor neurons (Ho et al., 1983).

\section{References}

Anderson, H. (1978) Postembryonic development of the visual system of the locust, Schistocerca gregaria. J. Embryol. Exp. Morphol. 45: 55-83.

Bate, C. M. (1976) Pioneer neurons in an insect embryo. Nature 260: $54-56$.

Bate, C. M., and E. B. Grunewald (1981) Embryogenesis of an insect nervous system. II. A second class of neuronal precursor cells and the origin of the intersegmental connectives. J. Embryol. Exp. Morphol. 61: 317-330.

Coggeshall, R. E., and D. W. Fawcett (1964) The fine structure of the central nervous system of the leech, Hirudo medicinalis. J. Neurophysiol. 27: 229-289.

Ferguson, B. (1981) Motor innervation of the chick hindlimb after dorsal-ventral limb rotations. Soc. Neurosci. Abstr. 7: 177.

Fernandez, J. (1980) Embryonic development of the glossiphoniid leech Theromyzon rude: Characterization of developmental stages. Dev. Biol. 76: 245-262.

Fernandez, J., and G. S. Stent (1980) Embryonic development of the glossiphoniid leech Theromyzon rude: Structure and development of the germinal bands. Dev. Biol. 78: 407-434.

Goodman, C. S., and N. C. Spitzer (1979) Embryonic development of identified neurones: Differentiation from neuroblast to neurone. Nature 280: 208-214.

Goodman, C. S., J. A. Raper, R. K. Ho, and S. Chang (1982) Pathfinding by neuronal growth cones during grasshopper embryogenesis. Symp. Soc. Dev. Biol. 40: 275-316.

Ho, R. K., and C. S. Goodman (1982) Peripheral pathways are pioneered by an array of central and peripheral neurones in grasshopper embryos. Nature 297: 404-406.

Ho, R. K., E. E. Ball, and C. S. Goodman (1983) Muscle pioneers: Large mesodermal cells that erect a scaffold for developing muscles and motoneurones in grasshopper embryos. Nature 301: 66-69.

Keshishian, H. (1980) The origin and morphogenesis of pioneer neurons in the grasshopper metathoracic leg. Dev. Biol. 80: 388-397.

Kramer, A. P., and J. R. Goldman (1981) The nervous system of the glossiphoniid leech Haementaria ghilianii. I. Identification of neurons. J. Comp. Physiol. 144: 435-448.

Kramer, A. P., and J. Y. Kuwada (1983) Formation of the receptive fields of leech mechanosensory neurons during embryonic development. J. Neurosci., in press.

Kuwada, J. Y. (1982) Primary axon outgrowth in embryonic leech neurons. In Neuronal Development: Cellular Approaches in Invertebrates, C. Goodman and K. Pearson, eds., NRP, pp. 877-881, MIT Press, Cambridge, MA.

Kuwada, J. Y., and W. B. Kristan (1981) Development of identified neurons in the leech CNS. Soc. Neurosci. Abstr. 7: 2.

Lance-Jones, C., and L. Landmesser (1980a) Motoneurone projection patterns in embryonic chick limbs following partial deletions of the spinal cord. J. Physiol. (Lond.) 302: 559580 .

Lance-Jones, C., and L. Landmesser (1980b) Motoneurone projection patterns in the chick hind limb following early partial reversals of the spinal cord. J. Physiol. (Lond.) 302: 581-602.

Landmesser, L. (1978a) The distribution of motoneurons supplying chick hind limb muscles. J. Physiol. (Lond.) 284: 371389.

Landmesser, L. (1978b) The development of motor projection patterns in the chick hind limb. J. Physiol. (Lond.) 284: 391414.

Landmesser, L., and D. G. Morris (1975) The development of functional innervation in the hindlimb of the chick embryo. J. Physiol. (Lond.) 249: 301-326.

Lent, C. M. (1973) Retzius cells: Neuroeffectors controlling mucus release by the leech. Science 179: 693-696.

Macagno, E. R. (1978) A mechanism for the formation of synaptic connections in the arthropod visual system. Nature 275: 318-320.

Macagno, E. R. (1980) Number and distribution of neurons in the leech segmental ganglions. J. Comp. Neurol. 190: 283302.

Muller, K. J., and U. J. McMahan (76) The shapes of sensory and motor neurons and the distribution of their synapses in the ganglia of the leech: A study using intracellular injection of horseradish peroxidase. Proc. R. Soc. Lond. Biol. 144: 481499.

Muller, K. J., J. G. Nicholls, and G. S. Stent (1981) Neurobiology of the Leech, Cold Spring Harbor Laboratory, Cold Spring Harbor, NY.

Murphey, R. K. (1981) The structure and development of a somatotopic map in crickets: The cercal afferent projection. Dev. Biol. 88: 236-246.

Nicholls, J. G., and D. A. Baylor (1968) Specific modalities and receptive fields of sensory neurons in the C.N.S. of the leech. J. Neurophysiol. 31: 740-756.

Ramon y Cajal, S. (1960) Studies on Vertebrate Neurogenesis, L. Guth, transl., Charles C Thomas Publishers, Springfield, IL.

Raper, J. A., M. Bastiani, and C. S. Goodman (1983a) Pathfinding by neuronal growth cones in grasshopper embryos. I. Divergent choices made by the growth cones of sibling neurons. J. Neurosci. 3: 20-30.

Raper, J. A., M. Bastiani, and C. S. Goodman (1983b) Pathfinding by neuronal growth cones in grasshopper embryos. II. Selective fasciculation onto specific axonal pathways. J. Neurosci. 3: 31-41.

Sawyer, R. T., F. Le Pont, D. K. Stuart, and A. P. Kramer (1981) Growth and reproduction of the giant glossiphoniid lecch Haementaria ghilianii. Biol. Bull. 160: 322-331.

Stewart, W. W. (1978) Functional connections between cells as revealed by dye-coupling with a highly fluorescent naphthal- 
imide tracer. Cell 14: 741-759.

Stuart, A. E. (1970) Physiological and morphological properties of motoneurones in the central nervous system of the leech. J. Physiol. (Lond.) 209: 627-646.

Weisblat, D. A., R. T. Sawyer, and G. S. Stent (1978) Cell lineage analysis of intracellular injection of a tracer. Science 202: 1295-1298.

Weisblat, D. A., G. Harper, G. S. Stent, and R. T. Sawyer (1980a) Embryonic cell lineages in the nervous system of the glossiphoniid leech Helobdella triserialis. Dev. Biol. 76: 58 78.

Weisblat, D. A., S. L. Zackson, S. S. Blair, and J. D. Young $(1980 \mathrm{~b})$ Cell lineage analysis by intracellular injection of fluorescent tracers. Science 209: 1538-1541.

Whitman, C. O. (1878) The embryology of Clepsin. Q. J. Microsc. Sci, 18: 215-315.

Whitman, C. O. (1887) A contribution to the history of germ layers in Clepsine. J. Morphol. 1: 105-182. 